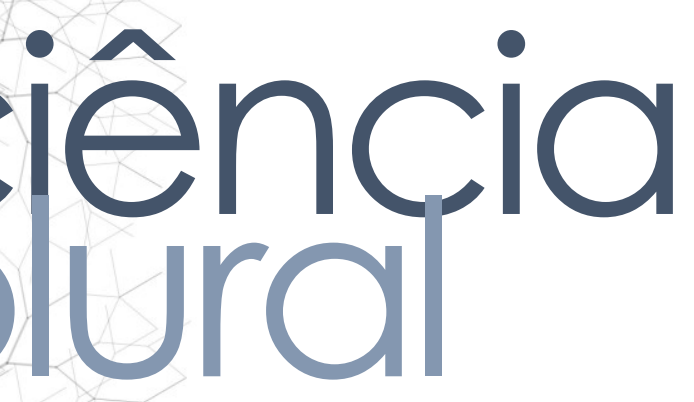

\title{
A LUDICIDADE COMO ESTRATÉGIA DE EDUCAÇÃO EM SAÚDE BUCAL NO CENTRO DE ATENÇÃO PSICOSSOCIAL ÁLCOOL E DROGAS: RELATO DE EXPERIÊNCIA
}

Ludicity as a statregy in oral health education at psychosocial care center for alcohol and drugs: experience report

La ludicidade como estratégia em la educación en salud bucal en el Centro de Atención Psicosocial de Álcohol y Drogas: informe de experiência

Caroline Vieira Alves • Cirurgiã- Dentista • Pós- Graduada pelo Programa de Residência Multiprofissional em Atenção Básica -EMCM/UFRN •

E-mail: carolinevieiralves@gmail.com

Tatiane Alves da Silva • Bacharel em Educação Física - UFRN •

E-mail: tatyanealves@yahoo.com.br

Eudes Euler de Sousa Lucena • Doutor em Psicobiologia -UFRN • Docente na Escola Multicampi de Ciências Médicas do RN - UFRN •

E-mail: eudeseuler@hotmail.com

Autora responsável pela correspondência:

Caroline Vieira Alves•E-mail: carolinevieiralves@gmail.com 


\section{RESUMO}

Introdução: A educação em saúde bucal tem um papel importante no processo de empoderamento dos usuários do Centro de Atenção Psicossocial Álcool e Drogas, um espaço especializado no atendimento psicossocial a esses usuários. A natureza dessas substâncias sejam elas lícitas (álcool e tabaco) ou ilícitas (alucinógenos, opióides, sedativos etc.) causam um efeito devastador para os tecidos bucais e prejuízo à qualidade de vida. Objetivo: Descrever uma oficina de construção de jogos para promover o cuidado em saúde bucal no referido Centro na cidade de Caicó, Rio Grande do Norte. Metodologia: Durante o segundo ano do Programa de Residência em Atenção Básica da Escola Multicampi de Ciências Médicas da Universidade Federal do Rio Grande do Norte, são realizados rodízios na Atenção Secundária e Terciária no Sistema de Saúde Municipal. A intervenção descrita ocorreu em maio/2019. Realizaram-se encontros abordando a temática da saúde bucal, conduzidos pela dentista residente com a participação da artesã, psicóloga e profissional de educação física. Estavam presentes nos encontros de 10 a 15 usuários, de ambos os sexos. Durante os três encontros foram realizados construção de jogos, utilização dos jogos produzidos, roda de conversa sobre saúde bucal e um quadro com orientações de higiene bucal. A atividade foi realizada no espaço destinado às oficinas de artesanato que faziam parte da rotina do serviço. Resultados: Foram produzidos quatro jogos educativos e um quadro com orientações de higiene bucal, que ficaram disponíveis para os usuários do serviço. Conclusões: Essa atividade além de ser uma oportunidade de ócio criativo pode contribuir com a compreensão dos conteúdos relacionados a saúde bucal que são abordados dentro do jogo, incentiva a discussão sobre o tema e estimula o autocuidado, reforçando e orientando as boas práticas de higiene.

Palavras-Chave: Jogos recreativos; Odontologia; Promoção da saúde; Saúde Mental.

\section{ABSTRACT}

Introduction: Oral health education has an important role in the process of empowering users of the Psychosocial Care Center for Alcohol and Drugs, a space specialized in psychosocial care for these users. The nature of these substances, whether licit (alcohol and tobacco) or illicit (hallucinogens, opioids, sedatives, etc.), has a devastating effect on oral tissues and impairs quality of life. Objective: To describe a game-building workshop to promote oral health care in that Center in the city of Caicó, Rio Grande do Norte. Methodology: During the second year of the Primary Care Residency Program at the Multicampi School of Medical Sciences at the Federal University of Rio Grande do Norte, there is a rotation within the services of secondary and tertiary care in the Municipal Health System. The described intervention took place in May/2019. Meetings were held addressing the theme of oral health, conducted by the resident dentist with the participation of the artisan, sychologist and physical education professional. 10 to 15 users of both sexes were esent at the meetings. During the three meetings, games were built and used, there also a conversation about oral health and a chart with oral hygiene guidelines was duced. The activity took place in the space destined for the craft workshops that e part of the service routine. Results: Four educational games and a chart with oral 
hygiene guidelines were produced, which were made available to service users. Conclusions: This activity, in addition to being an opportunity for creative leisure, can contribute to the understanding of content related to oral health that are addressed within the game, encourages discussion on the topic and stimulates self-care, reinforcing and guiding good hygiene practices.

Keywords: Recreational games; Dentistry; Health promotion; Mental health.

\section{RESUMEN}

Introducción: La educación en salud bucal tiene un papel importante en el proceso de empoderamiento de los usuarios del Centro de Atención Psicosocial de Alcohol y Drogas, un espacio especializado en la atención psicosocial de estos usuarios. La naturaleza de estas sustancias, ya sean lícitas (alcohol y tabaco) o ilícitas (alucinógenos, opioides, sedantes, etc.), tiene un efecto devastador sobre los tejidos bucales y perjudica la calidad de vida. Objetivo: Describir un taller de construcción de juegos para promover el cuidado de la salud bucal en ese Centro de la ciudad de Caicó, Rio Grande do Norte. Metodología: Durante el segundo año del Programa de Residencia de atención primaria en la Escuela multicampi de Ciencias Médicas de la Universidad Federal de Rio Grande do Norte, atención secundaria y terciaria se rotan en el sistema de salud municipal. La intervención descrita tuvo lugar en mayo/2019. Se realizaron encuentros abordando el tema de la salud bucal, conducidos por el dentista residente con la participación del artesano, psicólogo y profesional de educación física. En las reuniones estuvieron presentes entre 10 a 15 usuarios de ambos sexos. Durante los tres encuentros se construyeron juegos, se utilizaron juegos, una conversación sobre salud bucal y un cuadro con pautas de higiene bucal. La actividad se desarrolló en el espacio destinado a los talleres artesanales que formaban parte de la rutina del servicio. Resultados: Se elaboraron cuatro juegos educativos y una mesa con pautas de higiene bucal, que se pusieron a disposición de los usuarios del servicio. Conclusiones: Esta actividad, además de ser una oportunidad de ocio creativo, puede contribuir a la comprensión de contenidos relacionados con la salud bucal que se abordan dentro del juego, fomenta la discusión sobre el tema y fomenta el autocuidado, reforzando y orientando buenas prácticas de higiene.

Palabras clave: Juegos recreacionales; Odontología; Promoción de la salud; Salud mental. 


\section{Introdução}

Presente em diversos contextos, o jogo tem a potencialidade de representar a necessidade humana de prazer, festa e diversão. Desde a infância até a vida adulta estamos sempre envolvidos com jogos. Para Huizinga, historiador holandês, o jogo precede a cultura e a concepção de sociedade e é por intermédio dele que surgem comportamentos e expressões sociais, visto que a noção de jogo e o ímpeto para tal, não é uma experiência exclusiva do homem, sendo observado também entre os animais ${ }^{1}$.

O jogo pode ser entendido como uma ação espontânea, que carrega em si um sentido de tensão e alegria, gerando uma noção de existir diferente daquela experimentada na rotina. Deve ter ambiente e duração determinados, em que as regras postas são aceitas e respeitadas pelos participantes e tem no momento vivido seu sentido completo ${ }^{1}$.

Mas, qual seria o real sentido do jogo? O jogo vai além do sentido biológico e pode ter diversos significados para os envolvidos. $\mathrm{O}$ momento do jogo proporciona uma pausa na rotina, traz alegria e entusiasmo, sobretudo, quando insere o lúdico no cotidiano. O lúdico, refere-se ao estado de divertimento e satisfação na execução de uma atividade, é um elemento importante do jogo, mas não deve ser confundido com ele. O jogo por sua vez, pode ou não, abranger o sentimento de ludicidade em si, dependendo do ponto de vista avaliado ${ }^{2}$.

O jogo, porém, ao gerar uma atmosfera lúdica, torna esse momento mais agradável. Ele ainda tem a característica de ser um espaço de expressão, isso porque o lúdico do jogo é uma forma criativa de mediação entre o sujeito e sua experiência. Nele, existe a possibilidade de fazer um enfrentamento dos desafios, tomar consciência de suas ações e resultados, alterar o que considera insuficiente tendo maior clareza na resolução de problemas ${ }^{3}$.

Assim, pensar na educação em saúde utilizando jogos é uma alternativa atrativa ficiente para gerar interesse e aproximação aos conteúdos abordados ${ }^{4}$. Os jogos e ncadeiras são também uma ferramenta utilizada nos Centros de Atenção 
Psicossocial (CAPS) e destacam-se como formas de promover a saúde mental, uma vez que através deles estimula-se o pensar e o sentir de uma maneira diferente ${ }^{5}$.

Os CAPS foram criados em 2002, regulamentados pela portaria ministerial GM n³36, de 19 de fevereiro do mesmo ano e surgem em um cenário que busca um novo olhar ao modelo hospitalocêntrico. Essas instituições são fruto de um processo político e social complexo, denominado Reforma Psiquiátrica, que abrange diversas transformações culturais, sociais e de práticas no campo da saúde mental6,7.

Os CAPS possuem caráter substitutivo e visam promover além do acompanhamento clínico a reinserção social do indivíduo. A modalidade AD, voltado ao tratamento de usuários de álcool e outras drogas, é orientada pela perspectiva da política de redução de danos, oferece um tratamento baseado no projeto terapêutico individualizado de acompanhamento contínuo e além do atendimento individual, as unidades promovem ainda, atividades coletivas, oficinas terapêuticas e visitas domiciliares ${ }^{6}$.

Considerando os efeitos adversos do uso abusivo de álcool e outras drogas na cavidade bucal, é importante que sejam desenvolvidas atividades no sentido de orientar e prevenir agravos, além do tratamento curativo, motivando o autocuidado em saúde para os usuários desses dispositivos bem como em outros pontos da rede 8 .

Na odontologia, a abordagem lúdica, utiliza-se de diversos recursos, como jogos, brincadeiras, música, teatro, histórias e têm apresentado ótimos resultados na odontopediatria, facilitando a formação de vínculo, adesão ao tratamento além de proporcionar experiências mais prazerosas no ambiente odontológico 9 .

O uso dessas estratégias é comum na odontopediatria, com a finalidade de promover adesão ao tratamento odontológico por parte das crianças ${ }^{13}$, mas quando se trata de um público adulto, as atividades realizadas são comumente palestras, dinâmicas e rodas de conversa7 ${ }^{7}$ Porém outras profissões da saúde, principalmente a nfermagem, têm apresentado experiências exitosas quanto à utilização de jogos em vidades de educação em saúde para adolescentes e adultos'16,17,18,19.

Este trabalho tem por objetivo, descrever uma oficina de construção de jogos promover o cuidado em saúde bucal no CAPS AD da cidade de Caicó/RN, na 
qual foram utilizadas ferramentas lúdico educativas como estratégia para favorecer a construção do conhecimento e estimular o autocuidado em saúde bucal.

\section{Metodologia}

Estudo descritivo, do tipo relato de experiência, vivenciada pela residente do segundo ano de odontologia. A experiência relatada ocorreu no mês de maio de 2019 durante o rodízio dos residentes do Programa de Residência Multiprofissional em Atenção Básica da Escola Multicampi de Ciências Médicas, vinculada à Universidade Federal do Rio Grande do Norte, na Atenção Secundária, no Centro de Apoio Psicossocial - álcool e drogas (CAPS AD) da cidade de Caicó/RN.

O CAPS AD de Caicó foi fundado em 26 de abril de 2014 e está situado no bairro do centro. A unidade funciona das 7 às 17 horas e a média de usuários-dia é de 25 pessoas. Nele são atendidos além da população do município, pessoas de cidades vizinhas. A equipe multiprofissional é composta atualmente por: assistente social, psicóloga, enfermeira, profissional de educação física, médico clínico, médico psiquiatra, técnico em enfermagem e artesã, sendo um profissional de cada área. $\mathrm{O}$ tratamento é desenvolvido de forma individual e em grupos, inclui atividades físicas, oficinas terapêuticas e arte-terapia além da abordagem médica e psicológica. As unidades dispõem também de local para higiene, alimentação e repouso dos usuários, que passam o dia em atendimento no local.

A ideia inicial para desenvolver esta atividade surgiu quando um usuário do CAPS, solicitou que fosse realizado um momento para orientações sobre higiene e saúde bucal. Na perspectiva de desenvolver atividades diferentes e mais efetivas, foram planejadas intervenções lúdicas que pudessem envolvê-los de forma ativa na construção do conhecimento acerca do tema e inserir a ação na rotina do serviço. Assim, a dentista residente propôs atividades na forma de oficinas, com a temática de aúde bucal, que foi bem aceita pela equipe do CAPS AD e pelos usuários.

Foi sugerido a confecção de dois quebra-cabeças e um jogo da memória, por não jogos desse tipo no serviço. Além dos jogos, foi proposto também a construção de 
um quadro com orientações de saúde bucal. Para construção do quadro foi utilizada uma abordagem lúdica, os usuários deveriam associar as imagens com os textos, que estavam inicialmente embaralhados e que deveriam ser organizados em ordem para formar a sequência correta da escovação.

Durante a atividade todas as etapas da construção dos jogos e do quadro, foram executadas pelos usuários, que se organizaram para dividir as tarefas. Os materiais utilizados foram: imagens e textos impressos em papel, cola, papelão, isopor, plástico de revestimento transparente, papel colorido, régua, lápis e tesoura. As imagens utilizadas retratavam o cuidado em saúde bucal, os problemas mais comuns e instrumentos para higiene.

As atividades aconteceram durante as oficinas de artesanato, que faziam parte da rotina do CAPS AD e foram desenvolvidas pela dentista residente com auxílio da artesã, psicóloga e profissional de educação física. A participação nas oficinas não era obrigatória, ficando à critério dos usuários estar presente ou não nas atividades.

Foram realizados três encontros nos quais abordou-se a temática da saúde bucal de forma lúdica e o número de participantes variou de 10 a 15 usuários em cada oficina. No primeiro, foram confeccionados três jogos, sendo dois quebra-cabeças e um jogo da memória. No segundo encontro a atividade foi finalizada, tivemos a oportunidade de usufruir dos brinquedos construídos, promovendo a discussão e o autocuidado em saúde bucal a partir dos jogos e confeccionamos também caixas em origami para guardá-los.

Ainda no segundo encontro ao vivenciar os jogos, os usuários relataram maior dificuldade ao montar o quebra-cabeça por eles confeccionados, isso ocorreu devido ao tamanho das peças que ficaram menores que o planejado. Em outro momento, foi confeccionado novo quebra cabeça, com a mesma imagem, dessa vez em peças maiores, tornando-o mais atrativo para os usuários.

No terceiro encontro, foi proposto aos usuários a montagem de um quadro com rientações sobre escovação. Inicialmente, a abordagem sobre o tema aconteceu na ma de uma roda de conversa, que foi conduzida pela dentista residente. Este mento teve como objetivo compartilhar as experiências e saberes, tirar dúvidas dos 
usuários a respeito do tema, bem como orientá-los para a atividade proposta. A partir da combinação de imagens e textos que inicialmente estavam embaralhados, os usuários montaram e decoraram o quadro, que foi fixado próximo ao local onde os usuários realizavam a rotina higiene bucal.

\section{Resultados}

Como resultado dessa intervenção foram produzidos quatro jogos educativos, sendo três quebra-cabeças, todos com imagens relacionadas à higiene bucal e ainda um jogo da memória com ilustrações no intuito de vislumbrar as possibilidades que a higiene bucal pode oferecer. Essas imagens tinham como tema o atendimento na odontologia, escovação, cáries, o instrumental utilizado no consultório, o uso do fio dental e situações corriqueiras da prática da odontologia.

No processo de construção dos jogos foi realizado pelos usuários do serviço um quebra-cabeça que ficou com as peças no tamanho reduzido, gerando uma dificuldade maior na montagem, então este jogo foi refeito pela dentista residente que conduziu a intervenção. Esse novo quebra-cabeça possuía a mesma imagem do anterior, apenas suas dimensões foram alteadas para que as peças ofertassem maior facilidade na visualização da imagem a ser montada.

O último encontro contou com dois momentos, o primeiro foi uma roda de conversa, onde estavam presentes os usuários do CAPS AD e a dentista residente, nesse momento os usuários falaram sobre suas impressões, desde a construção dos jogos até o momento em que vivenciaram o jogo em si. Já no segundo momento, foram dadas instruções para construção do quadro com orientações de higiene bucal.

Logo após as instruções de construção do quadro, os usuários iniciaram a sua montagem e o fixaram próximo ao local destinado à higiene pessoal dos usuários daquele serviço. Assim, como resultado dessa ação, destaca-se além dos materiais produzidos, o acesso à outras possibilidades de lazer e à informações sobre higiene ucal. 


\section{ciênciána
plural}

Ao utilizar as ferramentas construídas, os usuários demonstraram satisfação em brincar com os jogos confeccionados por eles e ainda a motivação diante de novos estímulos cognitivos. Inicialmente, alguns preferiam apenas observar a brincadeira, mas logo que compreenderam as regras do jogo, apresentaram uma postura ativa na execução da atividade.

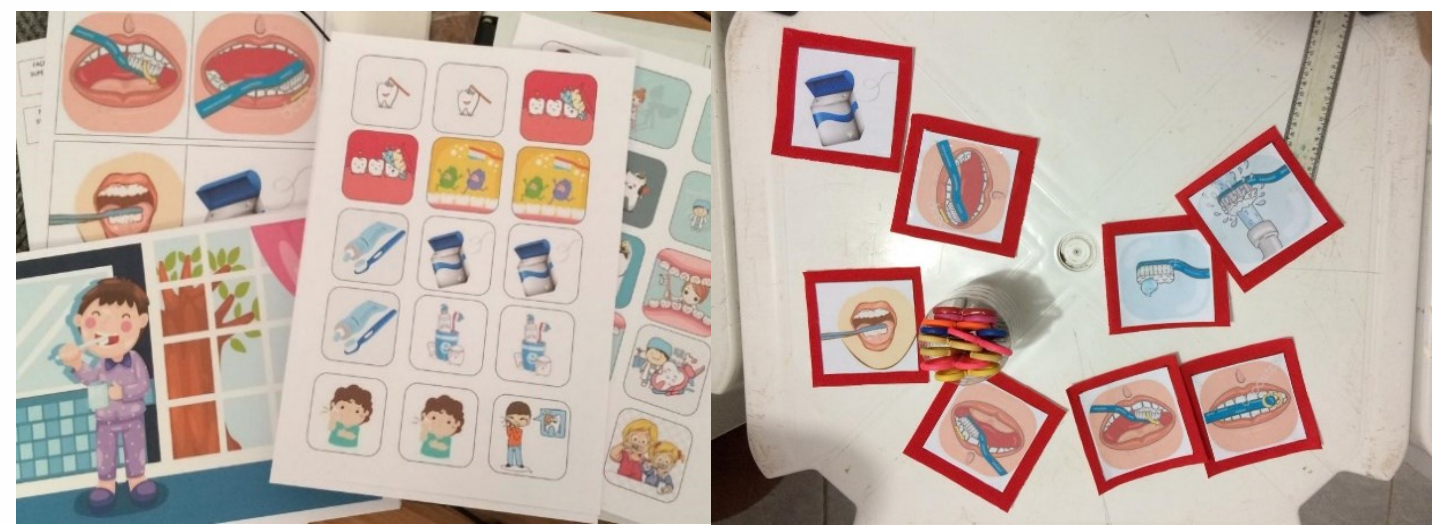

Figura 1. Imagens utilizadas para o quebra-cabeça, jogo da memória e para o quadro de orientações, Caicó-RN, 2019.

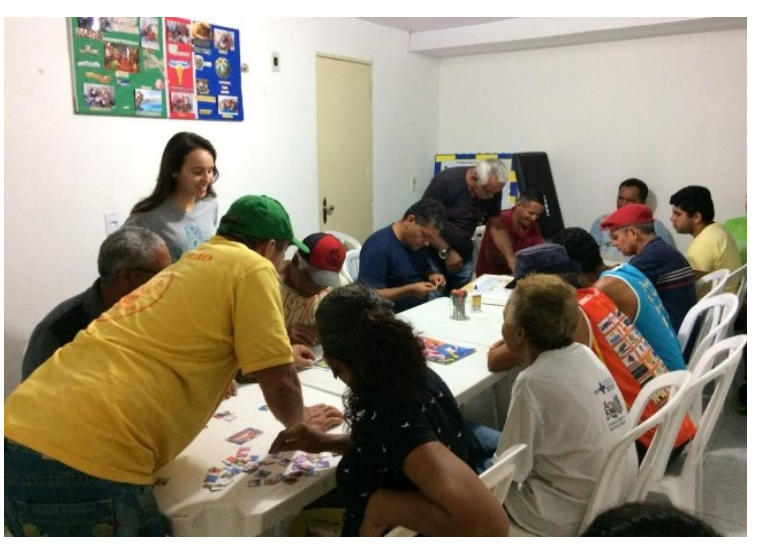

Figura 2. Material utilizado para confecção dos jogos, Caicó-RN 2019.

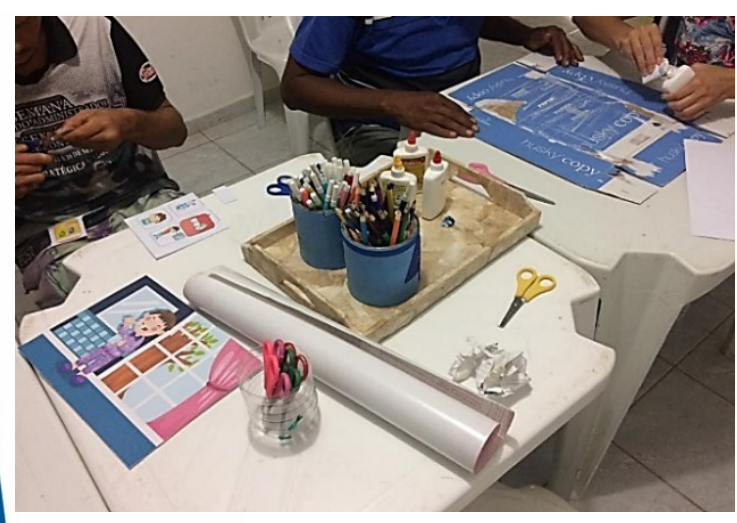

Figura 4. Usuários brincando com jogos confeccionados na oficina, Caicó-RN, 2019.

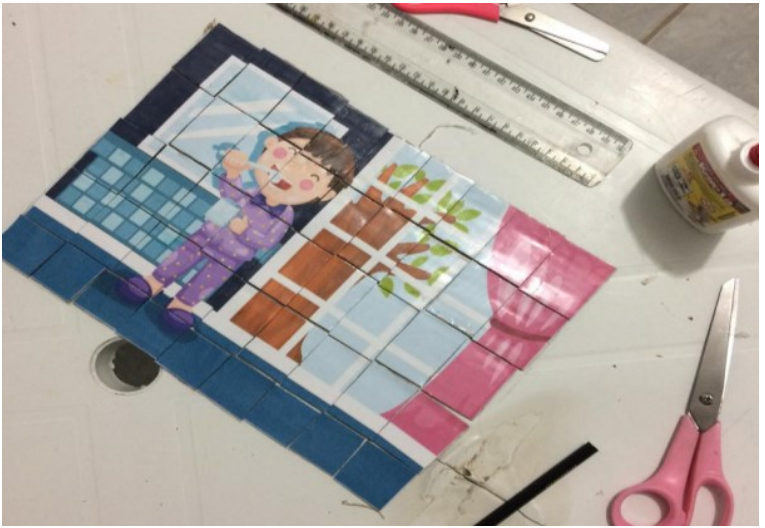

Figura 3. Quebra- cabeça finalizado, Caicó-RN 2019.

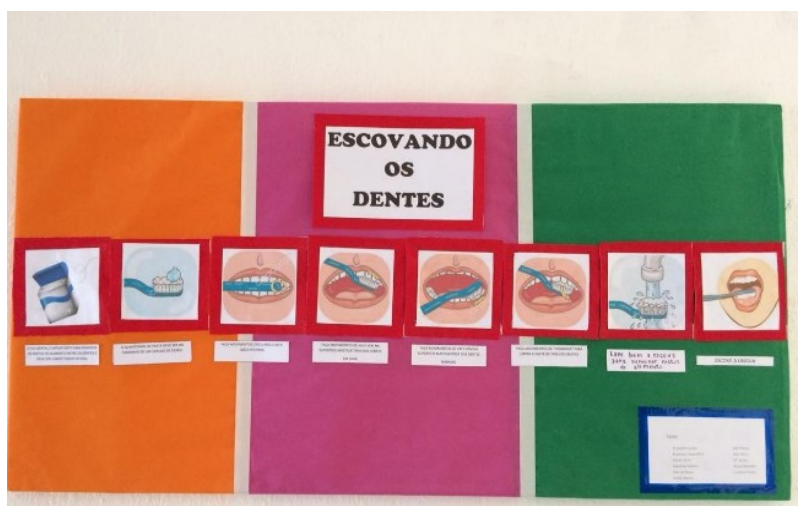

Figura 5. Quadro com orientações sobre escovação montado pelos usuários Caicó-RN, 2019. 


\section{Discussão}

O consumo abusivo de álcool e outras drogas, além de ser um grave problema social, acarreta danos à saúde do indivíduo. Na boca, as alterações observadas com maior frequência nesse público são: aumento do número de dentes perdidos e cariados, doença periodontal generalizada, fratura, desgaste, descamação, lesões de queimadura e manchamento da língua ${ }^{8,10}$.

Mesmo diante dessa realidade, observa-se ainda um distanciamento entre a assistência em saúde bucal e os serviços de saúde mental. A ausência de uma portaria que legitime a atuação do cirurgião-dentista no CAPS AD, restringe o acesso à saúde bucal preventiva e curativa para esse público, que muitas vezes são vítimas do preconceito nos serviços de saúde ${ }^{11}$. A inserção da residência multiprofissional no cenário do CAPS AD é uma forma de inserir o profissional dentista em um campo que carece de atenção e assim facilitar o acesso à informação sobre saúde bucal.

A vivência através da construção dos jogos com os usuários do CAPS AD, oferta uma possibilidade de aproximação entre a odontologia e a Rede de Atenção Psicossocial (RAPS). Uma vez que o CAPS AD não oferta estrutura ambulatorial é através da educação em saúde que seus usuários poderão ter acesso às informações de higiene bucal. De acordo com Oliveira, a utilização de jogos, construção de materiais e o público diversificado favorecem a preparação para atuação do dentista no cenário que ainda é pouco explorado por essa área 22.

Tendo em vista que a natureza das drogas, lícitas ou ilícitas, causam efeitos devastadores para os tecidos bucais e consequente prejuízo à qualidade de vida, a educação em saúde bucal tem um papel importante na orientação para os possíveis agravos gerados pelo uso de tais substâncias. Levando em consideração esses agravos, integração da odontologia nas equipes do CAPS AD é fundamental ${ }^{8}$.

As ações de educação em saúde, têm como principal objetivo possibilitar no jeito a autonomia para o cuidado preventivo, tornando-o capaz de agir, propor e inar a respeito da saúde individual e coletiva ${ }^{12}$. Diversas estratégias podem ser izadas por educadores para favorecer o processo de ensino-aprendizagem, dentre os jogos se destacam como uma possibilidade interessante. O jogo é um elemento 
harmonizador entre o lúdico e o educativo e tem o papel de motivar, sendo utilizado como ferramenta psicopedagógica de aproximação do usuário ao tema13.

Dentre as profissões da saúde, a odontologia é uma das que mais gera desconforto nos pacientes, seja pelos estereótipos que envolvem a profissão ou pela vulnerabilidade a qual o indivíduo vivencia durante o atendimento. Assim, associar a prática da educação em saúde bucal ao lúdico pode facilitar essa aproximação entre a odontologia e os usuários.

Na saúde, a utilização de jogos, visa a promoção da autonomia e incorporação de hábitos, e têm sido empregados principalmente com foco no público infantil. Da mesma forma abordagens lúdicas têm ganhado grande destaque em ambientes hospitalares, no tratamento de crianças, como forma de lidar com o sofrimento e procedimentos próprios da internação ${ }^{9,14,15}$.

Esse tipo de estímulo tem sido muito bem avaliado pelos participantes, como uma atividade empolgante, que torna mais agradável o momento de aprendizagem, facilitando a apreensão de conteúdos e estimulando a troca de experiências, uma vez que os usuários se sentem mais à vontade para participar e tirar dúvidas ${ }^{17,18,19}$. O que também pôde ser observado entre os usuários do CAPS AD durante o desenvolvimento das oficinas e da roda de conversa.

As oficinas terapêuticas ao mesmo tempo que favorecem a expressão subjetiva, respeito à diversidade e a atuação coletiva, oportuniza o desenvolvimento de habilidades cognitivas e motoras, contribuindo para o desenvolvimento da autonomia do usuário ${ }^{20}$. E por isso, são um recurso de grande valor na reabilitação psicossocial do indivíduo acompanhado no CAPS AD.

Aliar o momento de educação em saúde bucal à oficina de artesanato torna a atividade mais atrativa e envolvente, pois proporciona um momento onde os usuários podem descobrir na construção e experimentação do lúdico, uma forma diferente de tilizar o tempo e protagonizar através da criação, um lado novo do jogo, gerando conhecimento diante dele, tanto quanto criador como participante.

Uma outra estratégia utilizada foi a roda de conversa sobre saúde e higiene al. Esse foi um momento bastante interessante, uma vez que os usuários foram 
participativos e mostraram-se atentos às discussões. Segundo Costa, as rodas de conversa são importantes pois configuram-se espaços potentes para promoção da saúde mental, na medida que além de possibilitar a construção do conhecimento e autonomia do sujeito, são também um espaço de cuidado, onde é praticada a escuta e favorecida a formação vínculos sociais e afetivos ${ }^{21}$.

\section{Conclusões}

A intervenção realizada utilizando jogos para abordagem da saúde bucal, mostrou-se bastante produtiva, uma vez que incentiva a discussão sobre o tema e estimula o autocuidado, orientando e reforçando as boas práticas de higiene de forma descontraída e prazerosa.

A construção de jogos, além de ser uma alternativa econômica e de fácil reprodução, nos direciona a outras possibilidades de atividade para o profissional da Odontologia no espaço do CAPS AD. Desse modo, viabiliza ações de saúde bucal em um local onde não existe uma estrutura convencional para esse profissional, além de proporcionar um momento para novos estímulos cognitivos e o encontro com o lúdico de uma maneira inovadora.

\section{Referências}

1. Albornoz SG. Jogo e trabalho: do homo ludens, de Johann Huizinga, ao ócio criativo de Domenico De Masi. Cadernos de Psicologia Social do Trabalho. 2009 Jun 12(1): 75-92.

2. Arruda SG. A importância do lúdico na educação infantil e demais fases na visão da psicopedagogia. Miriade Científica. 2019 Ago 1(2): 1-15

3. Coscrato G, Pina JC, Mello DF. Utilização de atividades lúdicas na educação em saúde: uma revisão integrativa da literatura. Acta paul. enferm. 2010 Abr 23(2): 257-263.

4. Costa RRO, Filho JB, Medeiros SM, Silva MBM. As rodas de conversas como espaço de cuidado e promoção da saúde mental. Revista Brasileira Ciências da Saúde - Uscs. 2015 Mar 13 (43): 30-36. 
5. Cota ALS, Costa BJA. Atividades lúdicas como estratégia para promoção da saúde bucal infantil. Rev Saúde e Pesquisa. 2017 Set 10 (2): 365-371.

6. Falcão CAM, Santos RO, Pereira RMS, Silva TSO, Ferreira RS, Silva FWC, et al. Saúde bucal em dependentes químicos. RICS. 2015 Out 2 (3): 112-121.

7. Falkenberg MB, Mendes TPL, Moraes EP, Souza EM. Educação em saúde e educação na saúde: conceitos e implicações para a saúde coletiva. Ciênc. saúde coletiva. 2014 Mar 19(3): 847-852.

8. Fonseca LMM, Scochi CGS, Bis CEF, Serra SOA. Utilizando a criatividade na educação em saúde em alojamento conjunto neonatal: opinião de puérperas sobre o uso de um jogo educativo. Rev. bras. enferm. 2000 Jun 53(2): 301-310.

9. Fonseca LMM, Scochi CGS, Mello DF. Educação em saúde de puérperas em alojamento conjunto neonatal: aquisição de conhecimento mediado pelo uso de um jogo educativo. Rev. Latino-Am. Enfermagem. 2002 Abr 10(2): 166-171.

10. Gomes SCS, Rodrigues SR, Silva AB, Arruda AKS, Silva NM, Macedo RS, et al. Educação em saúde como instrumento de prevenção das parasitoses intestinais no município de Grajaú-MA. Pesquisa em Foco. 2016 Jul 21(1): 34-45

11. Huizinga J. Homo ludens: o jogo como elemento da cultura. 5th ed. São Paulo: Perspectiva; 2007.

12. Ibiapina ARS, Monteiro CFS, Alencar DC, Fernandes MA, Costa FAAI. Oficinas Terapêuticas e as mudanças sociais em portadores de transtorno mental. Esc. Anna Nery. 2017 Jul 21(3):1-8.

13. Brasil. Ministério da Saúde. Portaria GM n 336, de 19 de fevereiro de 2002. Define e estabelece diretrizes para o funcionamento dos Centros de Atenção Psicossocial. Diário Oficial da União 2002. Disponível em: bvsms.saude.gov.br/bvs/saudelegis/gm/2002/prt0336_19_02_2002.html

14. Brasil. Ministério da Saúde. Secretaria de Atenção à Saúde. DAPE. Coordenação Geral de Saúde Mental. Reforma psiquiátrica e política de saúde mental no Brasil. Documento apresentado à Conferência Regional de Reforma dos Serviços de Saúde Mental: 15 anos depois de Caracas. OPAS. Brasília, novembro de 2005 
15. Moura FA, Branco DC, Santos TOCG, Alves ACBA, Kataoka MSS, Pontes FSC, et al. Odontologia e saúde mental: experiência do PET Saúde no Centro de Atenção Psicossocial Álcool e Drogas. Revista da ABENO. 2019 Jul 19(2): 135 143.

16. Oliveira EE. Um auto relato sobre a participação no projeto ateliê do sorriso: um caminho percorrido da extensão à sociedade. Rev. Ciênc. Plural [Internet]. 12 de novembro de 2019 [citado 29 de outubro de 2020]; 5(3):72-8. Disponível em: https://periodicos.ufrn.br/rcp/article/view/18903

17. Oliveira RLB, Moreira SLB, Silva EDA, Azevedo LM, Felix VB, Lúcio IML. Atividades lúdicas como estratégia para a promoção de saúde bucal nas crianças e adolescentes hospitalizados. Gep News. 2017 Dez 1 (4): 33-38.

18. Pacheco FP, Garcez EMS. O jogo e o brincar: uma ação estratégica na promoção de saúde mental. Rev. Saúde Públ. Santa Cat. 2012 Abr 5 (1): 87-142.

19. Petty ALS, Souza MTCC, Monteiro TA. Intervenção com jogos em processo de desenvolvimento e aprendizagem. Psicologia da educação. 2019 Dez 49: 31-39.

20. Salles MM; Barros, S. Exclusão/inclusão social de usuários de um centro de atenção psicossocial na vida cotidiana. Texto \& Contexto Enfermagem. 2013 Set 22 (3): 704-712.

21. Sousa MG, Coelho MMF. Contando bem, que mal tem?: construção de tecnologia educativa sobre sexualidade para promoção da saúde com adolescentes. Revista Diálogos Acadêmicos. 2016 Dez 3 (2): 124-128.

22. Spagnol CA, Oliveira BKS, Candian ES, Santos RO, Manoel VCF, Moreira AR. O jogo como estratégia de promoção de qualidade de vida no trabalho no centro de material e esterilização. R. Enferm. Cent. O. Min. 2015 Out 5 (2):1562-1573. 